Linköping Studies in Science and Technology. Thesis No. 1628

Licentiate Thesis

\title{
Aberration-Corrected Analytical Electron Microscopy of \\ Transition Metal Nitride and Silicon Nitride Multilayers
}

Amie Fallquist

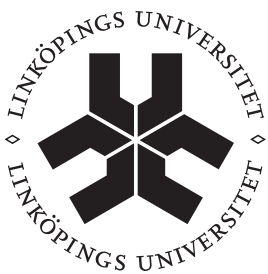

Linköping University INSTITUTE OF TECHNOLOGY

LIU-TEK-LIC-2013:62

Thin Film Physics Division

Department of Physics, Chemistry and Biology Linköping University, SE-581 83 Linköping, Sweden

Linköping, 2013 
ISBN: 978-91-7519-470-7

ISSN 0280-7971

Printed by LiU-Tryck, 2013 


\section{Abstract}

Two multilayer thin films have been studied: $\mathrm{TiN} / \mathrm{SiN}_{\mathrm{x}}$ and $\mathrm{ZrN} / \mathrm{SiN}_{\mathrm{x}}$. A double-corrected transmission electron microscope (TEM) was utilized for imaging and spectroscopy. Imaging was carried out in scanning mode (STEM) for all samples. Energy dispersive X-ray (EDX) spectrometry was used for chemical mapping of the $\mathrm{ZrN} / \mathrm{SiN}_{\mathrm{x}}$ samples and electron energy loss spectrometry (EELS) for atomic coordination of the nitrogen in the $\mathrm{TiN} / \mathrm{SiN}_{\mathrm{x}}$ samples.

In the $\mathrm{TiN} / \mathrm{SiN}_{\mathrm{x}}$ multilayer the structure of the epitaxially stabilized cubic $\mathrm{SiN}_{\mathrm{x}}$ was investigated. The high-resolution STEM images were compared with image simulations of $\mathrm{SiN}_{\mathrm{x}}$ in $\mathrm{B} 1$ (sodium chloride) and $\mathrm{B} 3$ (zinc blende) configurations and were found to be most similar to the B1 configuration. Core-loss EEL spectra were compared with calculated spectra and corroborated a resemblance with the $\mathrm{B} 1$ configuration.

The $\mathrm{ZrN} / \mathrm{SiN}_{\mathrm{x}}$ multilayers were initially believed to show a similarity to $\mathrm{TiN} / \mathrm{SiN}_{\mathrm{x}}$ but further investigations with $\mathrm{STEM}$ showed that the $\mathrm{SiN}_{\mathrm{x}}$ is amorphous. For samples deposited at $800{ }^{\circ} \mathrm{C}$ a SiN $\mathrm{Sin}_{\mathrm{x}}$ layer thickness $\leq 6 \AA$ the $\mathrm{SiN}_{\mathrm{x}}$ forms precipitates at grain boundaries and surface defects of the $\mathrm{ZrN}$ resulting in a columnar distribution of the $\mathrm{SiN}_{\mathrm{x}}$, which was further revealed by EDX. For such samples the $\mathrm{ZrN}$ grows by epitaxial lateral overgrowth. For samples deposited at $800^{\circ} \mathrm{C}$ but with a $\mathrm{SiN}_{\mathrm{x}}$ layer thickness of $6 \AA$ the $\operatorname{SiN}_{\mathrm{x}}$ starts to form more laterally extending layers and for thicknesses $\geq 8 \AA$ the $\mathrm{SiN}_{\mathrm{x}}$ grows into continuous, amorphous layers causing the following $\mathrm{ZrN}$ layers to assume a polycrystalline microstructure. The transition from epitaxial $\mathrm{ZrN}$ with columnar, amorphous SiNx, to multilayers of polycrystalline $\mathrm{ZrN}$ and amorphous $\mathrm{SiN}_{\mathrm{x}}$ layers appears at an even smaller thickness of $\mathrm{SiN}_{\mathrm{x}}$ if the deposition temperature is lowered, which is explained by the lowered adatom mobility. 



\section{List of Publications}

PAPER 1

Evidence for B1-cubic $\mathrm{SiN}_{\mathbf{x}}$ by Aberration-Corrected Analytical STEM

A. Fallqvist, W. Olovsson, L. Hultman, P.O.Å. Persson

In manuscript

PAPER 2

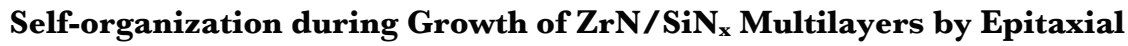
Lateral Overgrowth

A. Fallqvist, N. Ghafoor, H. Fager, L. Hultman, P.O.Å. Persson

Accepted for publication in Fournal of Applied Physics (2013) 



\section{Acknowledgements}

There are a lot of people that have made this work possible, with intellectual and practical as well as emotional support. The ones I want to thank the most are:

- my supervisor Per Persson,

- my co supervisor Lars Hultman,

- my co authors,

- our technician Thomas Lingefelt,

- my colleges in the Thin Film, Plasma and Nanostructured Material groups, especially Cecilia and Hanna,

- the administrative staff at the IFM department,

- my family, cats and friends,

- and last, but not least - Fakob! 



\section{Table of Contents}

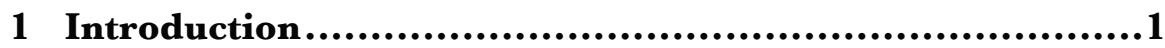

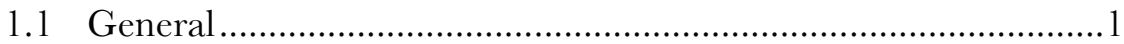

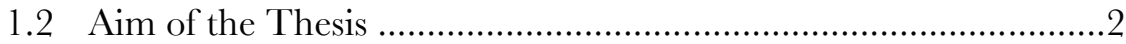

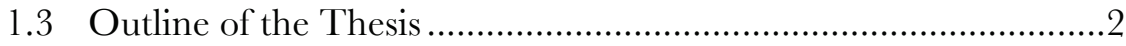

2 Materials .........................................................3

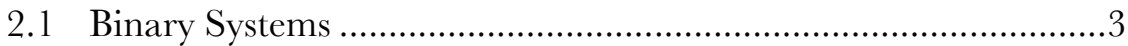

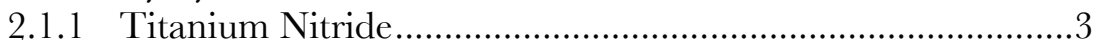

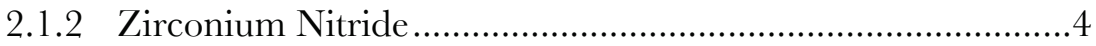

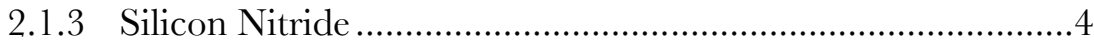

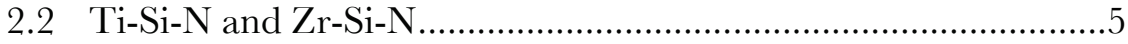

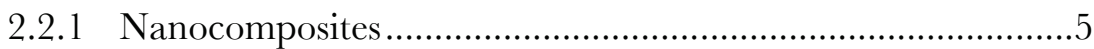

2.2.2 Multilayers ……............................................................

3 Thin Film Growth and Synthesis .............................7

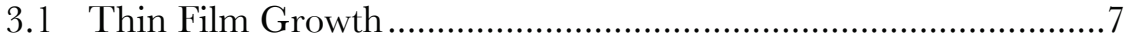

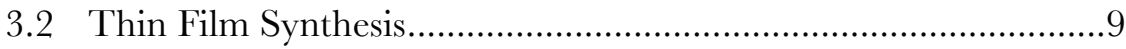

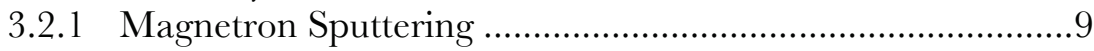

4 Characterization Techniques ............................... 13

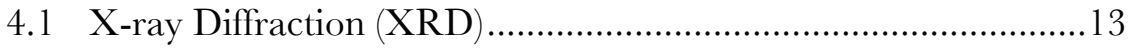

4.2 Transmission Electron Microscopy Imaging ............................... 14

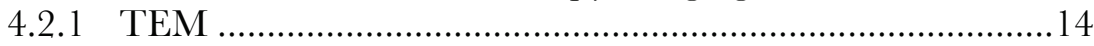

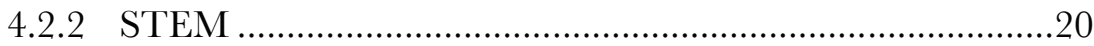

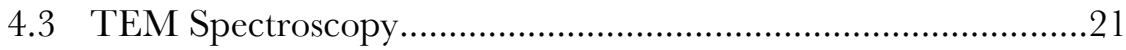

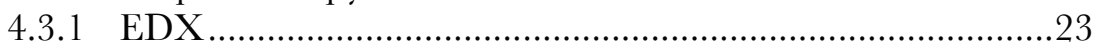

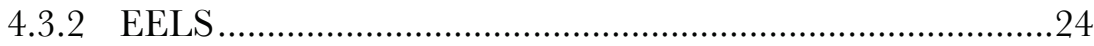

5 Summary of Papers.......................................... 27

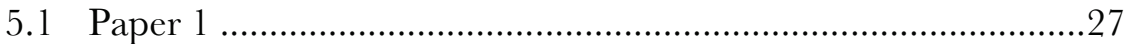

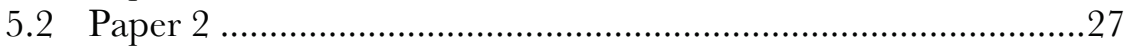

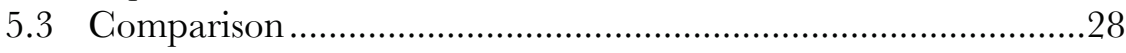

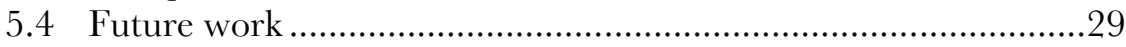

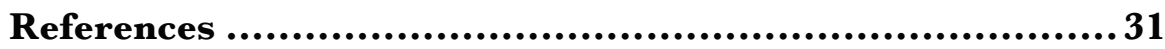

Paper 1 .............................................................. 35

Paper 2 ......................................................... 53 



\section{1 \\ Introduction}

\subsection{GeneraL}

Coatings are found all around us in our everyday life. They may be functional, as the sticky strip on the backside of a Post-It, decorative, like the metallic finish on plastic buttons of electronic consumer products, or both, as in the case of car paint, which is both protective and decorative. A sub category of coatings are thin films where the thickness is less than a couple of micrometers and can be made as thin as a few, or even single, atomic layers. Such thin coatings can be found in everyday objects such as mirrors, where the reflection is enabled by the thin metallic layer on the backside, glasses, both antireflective and protective films are common on the lenses as well as decorative coatings on the frames, and electronic products, both on the casing and in the actual electronics and contacts. But they are, needless to say, also utilized in the industry, as e.g. protective coatings of cutting tools. In the case of cutting tools one material that has been utilized for the last four decades is titanium nitride (TiN). This material has also been given improved mechanical and chemical properties by the addition of a third element such as silicon [1] or aluminum [2].

There are numerous ways of depositing coatings, where perhaps the simplest is a brush and a can of coating in liquid form. But for thin film coatings more refined techniques need to be employed, where a common technique is vapor deposition. The deposition process will, in combination with the substrate to be coated, determine the properties of the product such as mechanical and chemical behavior, and hence the development of this process is important for getting better films. However, to understand the cause of the film properties and the structure, the physics behind must also be understood. This means that the development of characterization techniques, analysis and theoretical understanding are equally important. 
A thin film can have the form of e.g. a solid solution, a nanocomposite or a multilayer, all depending on the desired properties in combination with the physical conditions. Solid solutions and nanocomposites are formed during the deposition of all the included elements at the same time while multilayers are usually formed by alternate deposition of the elements. Because of the possibility to control the layer deposition in multilayers, the properties of such thin films can relatively easily be connected with specific thicknesses and compositions of the layers and thereby be modified by varying these parameters. This can be utilized in e.g. optical coatings where reflectance and transmittance can be tuned by the refractive index and thickness of the layers. Furthermore the mechanical and chemical properties of a thin film can be changed by employing multilayers as in the case of titanium nitride and silicon nitride ( $\mathrm{SiN}$ ) multilayers, which have improved hardness as well as thermal stability compared to monolithic titanium nitride [3].

\subsection{AIM OF THE THESIS}

This study focuses on structural and chemical characterization of multilayers of TiN and SiN, and $\mathrm{ZrN}$ (zirconium nitride) and SiN. The main technique has been analytical transmission electron microscopy (TEM).

The challenge of the TiN/SiN multilayer study has been to identify the crystalline structure of the epitaxially stabilized SiN found when deposited in thin $(\lesssim 13 \AA)$ layers between crystalline TiN layers. The structure was previously found to be cubic, but which specific cubic structure the SiN exhibits has been debated for nearly a decade.

For the $\mathrm{ZrN} / \mathrm{SiN}$ the motif was to see if $\mathrm{SiN}_{\mathrm{x}}$ could be epitaxially stabilized also between $\mathrm{ZrN}$, which in many aspects is similar to TiN, and which structure the $\mathrm{SiN}$ would assume.

\subsection{OutLine Of The Thesis}

The thesis starts with an introduction to the materials systems involved the appended papers. In chapter 3 a general description of thin film growth and deposition will be given, as well as magnetron sputtering, which is the specific deposition technique used for the films in the papers. Chapter 4 describes the characterization techniques utilized and focuses mainly on transmission electron microscopy and spectroscopy. The final chapter contains a summary of the papers and conclusions from the research. 


\section{2 Materials}

The films studied in Paper 1 and 2 are based on multilayers consisting of alternating transition metal nitride $\left(\mathrm{T}_{\mathrm{m}} \mathrm{N}\right)$ and silicon nitride $\left(\mathrm{SiN}_{\mathrm{x}}\right)$ layers. In Paper 1 the transition metal is titanium $(\mathrm{Ti})$ and in Paper 2 it is zirconium $(\mathrm{Zr})$. The development of these multilayers has its origin in the nanocomposites of $\mathrm{T}_{\mathrm{m}}-\mathrm{Si}-\mathrm{N}$ systems. Therefore both nanocomposites and multilayers of the Ti-Si-N and $\mathrm{Zr}-\mathrm{Si}-\mathrm{N}$ systems will be described here.

\subsection{BinARY Systems}

\subsubsection{Titanium Nitride}

Materials in the Ti-N system exist in a couple of different phases as e.g. tetragonal $\mathrm{Ti}_{2} \mathrm{~N}$ and low nitrogen content hexagonal $\alpha$-Ti. The most commonly employed phase, however, is the cubic (c-) $\mathrm{TiN}_{\mathrm{x}}$ which has a $\mathrm{NaCl}$ structure with lattice parameter $4.24 \AA$ [4], see Figure 2.1 a) and a broad composition range of $0.6<\mathrm{x}<1.0$ at $1400^{\circ} \mathrm{C}$ [5].

The bonding structure of $\mathrm{TiN}$ is a mixture of covalent, metallic and ionic bonds [6] that causes the material to have a variety of properties. The metallic bonding leads to TiN being electrically conductive which is employed in the microelectronic industry where it is utilized as a diffusion barrier while still enabling charge transfer [7]. The covalent bonding causes it to be a ceramic with high hardness of $\sim 20 \mathrm{GPa}$ for single crystal TiN [8]. By incorporating lattice defects during the deposition, the hardness can be increased up to $~ 30 \mathrm{GPa}$ [9]. In addition TiN is wear and corrosion resistant, and as such has been utilized for protective coating on cutting tools. Further, stoichiometric TiN has a golden color that can also be varied by changing the composition, which makes it useful for decorative coatings. 
A drawback of TiN is that it oxidizes at temperatures $\gtrsim 450{ }^{\circ} \mathrm{C}[10]$. But with the addition of e.g. silicon, better oxidation resistance can be obtained and also gain the benefit of increasing hardness, as will be described in 2.2.

\subsubsection{Zirconium Nitride}

Cubic $\mathrm{ZrN}$ resembles c-TiN in appearance, structure and mechanical properties. It has a similar golden color that can be altered by varying the composition [11] and it has the same crystalline structure, B1 (Figure 2.1 a), but with a slightly larger lattice parameter of $4.58 \AA$ [12]. In addition it can be used as a wear-resistant coating with a similar hardness to TiN ( $25 \mathrm{GPa}$ ) [13]. Unfortunately it also lacks in oxidation resistance at about the same temperature of $\gtrsim 450{ }^{\circ} \mathrm{C}$ [14].

a)

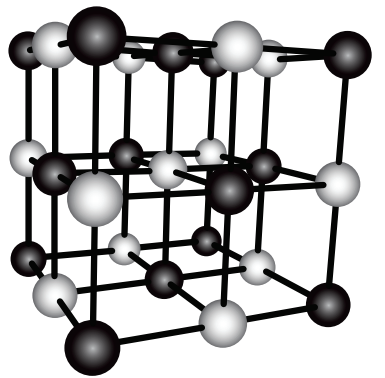

b)

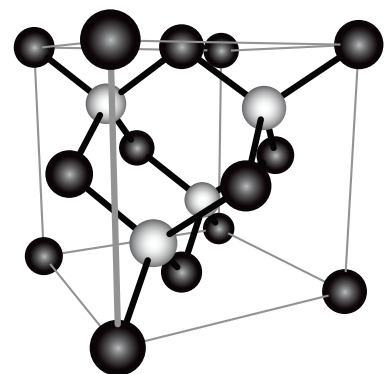

Figure 2.1 Crystal structures of type a) $\mathrm{B} 1(\mathrm{NaCl})$ and b) $\mathrm{B} 3(\mathrm{ZnS})$

\subsubsection{Silicon Nitride}

The most common form of silicon nitride is $\mathrm{Si}_{3} \mathrm{~N}_{4}$ which exists in four different phases: hexagonal $\alpha$ - and $\beta$ - [15], amorphous (a-) [15], and cubic spinel $\gamma-\mathrm{Si}_{3} \mathrm{~N}_{4}$ that is formed at high pressure and high temperature but metastable in air at ambient pressures down to $\sim 400{ }^{\circ} \mathrm{C}$ [16]. Of these, the $\gamma-\mathrm{Si}_{3} \mathrm{~N}_{4}$ has the highest hardness of $>35 \mathrm{GPa}$ [17] [18], but because of the strong covalent bonding in $\mathrm{Si}_{3} \mathrm{~N}_{4}$ the amorphous phase [19], with a hardness of $25 \mathrm{GPa}$ [20], is the most common when grown as a thin film.

In the work of for instance Söderberg et al. [21] and Hultman et al. [22], a metastable, cubic phase of silicon nitride was found when grown in a multilayer of $\mathrm{TiN}$ and $\mathrm{SiN}_{\mathrm{x}}$ (the $\mathrm{x}$ indicating that the stoichiometry is undetermined). Hultman et al. [22] showed that the $\operatorname{SiN}_{\mathrm{x}}$ will be epitaxially stabilized when deposited with a layer thickness $\lesssim 5 \AA$ and locally stabilized up to $13 \AA$ of $\operatorname{SiN}_{\mathrm{x}}$. The suggestion was first that $\operatorname{SiN}_{\mathrm{x}}$ with a B1 structure would have the best lattice match to c-TiN [21]. 
However, a B1 structure implies an octahedral bonding configuration, i.e. each $\mathrm{Si}$ atom coordinating six $\mathrm{N}$ atoms, whereas $\mathrm{SiN}_{\mathrm{x}}$ prefers tetrahedral bonding where each $\mathrm{Si}$ atom coordinates only four $\mathrm{N}$ atoms. A cubic structure that would satisfy that is the zinc blende, B3, structure shown in Figure $2.1 \mathrm{~b}$ ). However, the results from Paper 1 show that the measurements, when compared to simulations and calculations, indicate a B1 like structure for the $\mathrm{SiN}_{\mathrm{x}}$ challenging the more stable bonding geometry (B3) for bulk material [23].

\subsection{TI-SI-N AND ZR-SI-N}

\subsubsection{Nanocomposites}

The lack of oxidation resistance for $\mathrm{TiN}, \mathrm{ZrN}$ and other $\mathrm{T}_{\mathrm{m}} \mathrm{N}$ contributed to the research of adding an element to make a ternary nitride. One such element often applied, which is found in both papers presented in this work, is silicon that is more or less immiscible in $\mathrm{T}_{\mathrm{m}} \mathrm{N}$. For very small amounts of $\mathrm{Si}$ addition a single-phase film may be produced, but often just a few at. \% Si results in a nanocomposite film consisting of nanocrystalline $\mathrm{T}_{\mathrm{m}} \mathrm{N}$ grains in a $\mathrm{SiN}_{\mathrm{x}}$ matrix. Depending on the deposition conditions and the transition metal incorporated, the thickness and structure of the matrix, or tissue phase can be varied. This in turn improves not only the chemical properties but also the mechanical properties. It has been found that the hardest nanocomposite films have an improved hardness compared to the binary nitride when the $\mathrm{SiN}_{\mathrm{x}}$ layer thickness is $\sim 1$ monolayer (ML) [24].

The addition of Si to both $\mathrm{TiN}$ and $\mathrm{ZrN}$ has been reported to enhance properties such as oxidation resistance and hardness [25], [26]. There are however some differences between the Ti-Si-N and Zr-Si-S systems, e.g. maximum hardness dependence of the $\mathrm{Si}$ content and the decomposition mechanisms.

\subsubsection{Multilayers}

Another way to improve both oxidation resistance and hardness is to make two-dimensional nanocomposites, called nanolaminates or more commonly multilayers. Instead of a self-organized structure of $\mathrm{T}_{\mathrm{m}} \mathrm{N}$ nanocrystals in a tissue phase, layers of crystalline $\mathrm{T}_{\mathrm{m}} \mathrm{N}$ are grown alternately with e.g. $\mathrm{SiN}_{\mathrm{x}}$ by sequentially depositing the two materials. Depending on the included materials and deposition parameters the layers may grow epitaxially in which case the multilayer is called superlattice. In the case of $\mathrm{TiN} / \mathrm{SiN}_{\mathrm{x}}$ multilayers, depending on the thickness of the $\mathrm{SiN}_{\mathrm{x}}$ layers, the result can be either epitaxial, in which 
case it is called a superlattice (for $\operatorname{SiN}_{\mathrm{x}}$ thickness 7-10 $\AA$ ), or consist of polycrystalline TiN and amorphous $\mathrm{SiN}_{\mathrm{x}}$ [27]. The creation of such multilayers can also give more insight into the structure of the corresponding nanocomposites since multilayers facilitate interfacial studies with e.g. transmission electron microscopy. It was by the study of $\mathrm{TiN} / \mathrm{SiN}_{\mathrm{x}}$ multilayers that Hultman et al. could investigate the properties correlation to the $\mathrm{TiN} / \mathrm{SiN}_{\mathrm{x}}$ interface structure and chemistry [22].

Analogous to $\mathrm{TiN} / \mathrm{SiN}_{\mathrm{x}}$ multilayers, $\mathrm{ZrN} / \mathrm{SiN}_{\mathrm{x}}$ multilayers have been attempted. However, there has only been one article published this far. In that article Dong et al. utilize uncorrected TEM, which is not a sufficient method for structure analysis and therefore such multilayers have been further studied in Paper 2. The result of the study showed that the multilayers are dissimilar to those described for $\mathrm{TiN} / \mathrm{SiN}_{\mathrm{x}}$; instead of epitaxially stabilized c-SiN ${ }_{\mathrm{x}}$ between c-TiN layers the $\mathrm{SiN}_{\mathrm{x}}$ seem to form columnar, amorphous precipitates for similar deposition parameters. 


\section{3 \\ Thin Film Growth and Synthesis}

\subsection{Thin FILM GROWTH}

Thin film growth can be seen as a phase transformation where vapor phase atoms condensate on a substrate to nucleate and form islands that grow and merge into a film. For the initial stage of the growth, essentially three growth modes [28] exist (see Figure 2.1):

- Frank-van der Merve, where the film grow in layer-by-layer mode

- Volmer-Veber, also called island growth

- Stranski-Krastanov, which can be seen as a combination of initial layer-by-layer growth followed by island growth

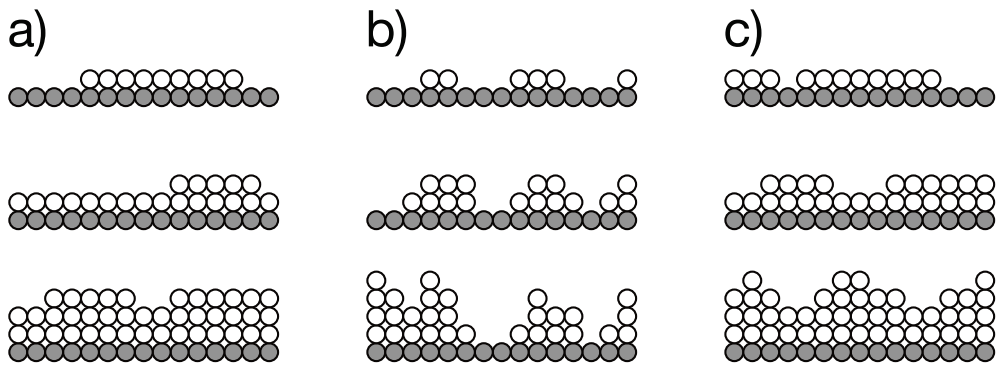

Figure 3.1 Growth modes: a) Frank-van der Merve, b) Volmer-Weber, and c) Stranski-Krastanov [28]

The structure of the resulting film will be determined by the surface diffusivity of the adatoms and the bulk diffusivity of the atoms in the film. The diffusivities depend on the temperature and energy of the system and can be varied by changing the substrate temperature. In addition, the surface diffusivity can be varied by the kinetic energy of ions accelerated towards the substrate surface, e.g. by substrate bias. The structure dependence on these parameters can be simplified into three different structure zones [29] shown in Figure 3.2. Zone 1 corresponds to low temperature and energy, leading to negligible adatom diffusion. The 
atoms therefore get trapped at high-energy lattice positions, which result in many nucleation sites and a columnar, porous film. With deposition parameters corresponding to zone $\mathrm{T}$ the surface diffusion becomes significant but bulk diffusion is still hindered by grain boundaries. This will allow the initial islands to grow, resulting in $\mathrm{V}$-shaped grain. However, further deposition will only yield a columnar film since the grains cannot coalesce. In zone 2 the temperature and energy are high enough to enable both surface and bulk diffusion which result in larger columns that may coalesce or recrystallize.

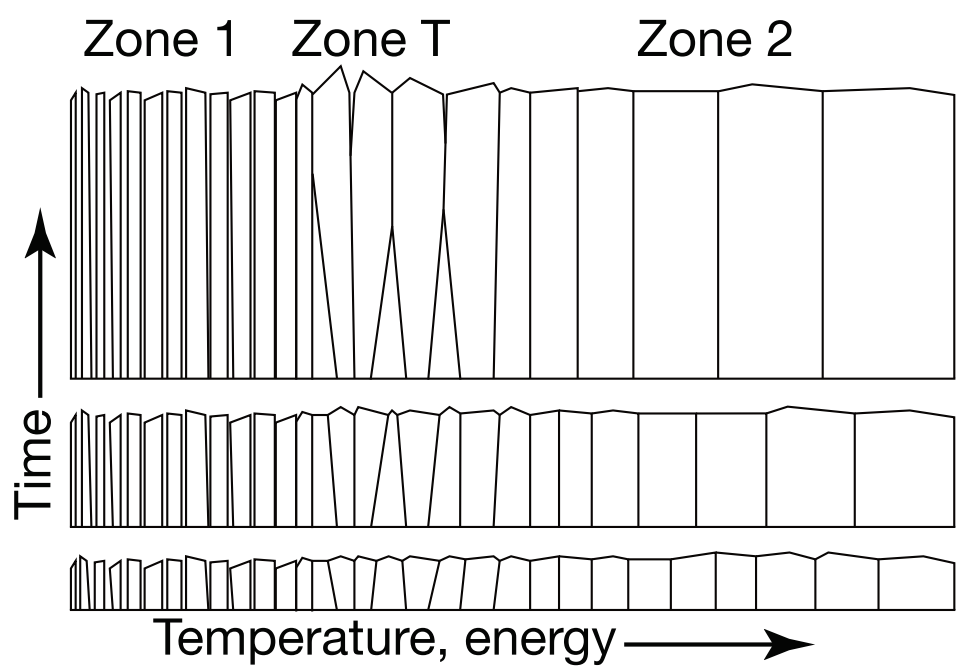

Figure 3.2 Structure zone models

In addition, the structure will also depend on the deposition rate and the lattice match between film and substrate. A low deposition rate will allow the atoms more time to move on the surface and find ideal energy minima where the atom can relax, before the next adatom arrives at the surface and potentially interferes with the initial adatom. The low deposition rate enhances the possibility to form large grains or single crystalline films while, on the opposite, high deposition rates will result in a defective, polycrystalline or amorphous films. A good lattice match will enable epitaxial film growth. The more alike the lattice parameter of the substrate and the film, the less strained the resulting film will be. If the lattice mismatch is too large the film might be relaxed by introducing dislocations and lattice defects which in turn results in a semi coherent or even incoherent interface between substrate and film.

If the growth is initiated on a surface consisting of a material on which nucleation is favorable, but where the surface is partially covered with islands of a material on which nucleation is unfavorable, the film may 
grow in a manner called epitaxial lateral overgrowth (ELO) [30]. This type of growth is seen for some of the films in Paper 2. In ELO nucleation will start on the favored areas of the surface, grow vertically in an epitaxial fashion, until the film is as thick as the islands. At this point the film proceeds to grow laterally across the islands with preserved epitaxial relation. This technique was first developed for manufacturing silicon over insulators and dielectrically isolated silicon islands but has become useful in other semiconductor manufacturing applications such as $\mathrm{GaN}$ [31].

\subsection{ThIn FILM SyNTHESIS}

Among the different ways to deposit thin films the most common one is from vapor phase. The vapor can either be a gas mixture containing atoms and molecules which chemically reacts to create the film on a substrate, called chemical vapor deposition (CVD), or it can be a vapor of the evaporated or sublimated source material which condensates on the substrate, called physical vapor deposition (PVD). These two techniques also differ in what you can deposit. GVD usually need high temperatures close to thermal equilibrium and prevents the use of heat sensitive substrates. On the other hand, an advantage of this technique is that all areas in contact with the vapor will be deposited and hence complicated structures can be coated. In PVD the deposition is only linein-sight of the source but deposition can be carried out at much lower temperatures. This allows the use of a wider range of substrate materials and the possibility to deposit metastable structures.

When employing a PVD technique, the vapor can be formed by evaporating the material thermally, as in e.g. thermal evaporation and cathodic arc evaporation, or by sputtering. In both papers of this work the films were deposited with the latter, more precisely reactive dc magnetron sputtering.

\subsubsection{Magnetron Sputtering}

In its basic form the setup for magnetron sputtering consists of a vacuum chamber connected to a system of pumps to achieve the required low pressure and a gas inlet for sputtering gas and optional reactive gases, and the source material, called target, and a substrate, both connected to voltage supplies (see Figure 3.3 a). The vacuum is required to minimize contamination and to enable control of the composition and structure of the films. But to be able to sputter the source material a sputtering gas is introduced via a gas inlet. This gas is usually an inert gas, where the most common is argon (which was employed for all films in this work). 
Although inert, Ar naturally contains some electrons and ions that can be affected by an electric field. By applying a negative voltage to the target the naturally occurring electrons will be repelled and accelerated from the target, which enables ionization of the gas. The positive ions will instead be attracted towards the target where they collide and either reflect or cause the ejection of mostly target atoms and ions, but also some secondary electrons and photons, as illustrated in Figure $3.3 \mathrm{~b}$. The secondary electrons will be rejected from the negatively charged target and hence also contribute towards ionization of the sputtering gas which with the right parameters will become a self-sustained plasma. The neutral target atoms, i.e. the main species to be ejected, will mostly be sputtered in the forward direction and finally condense on the substrate.

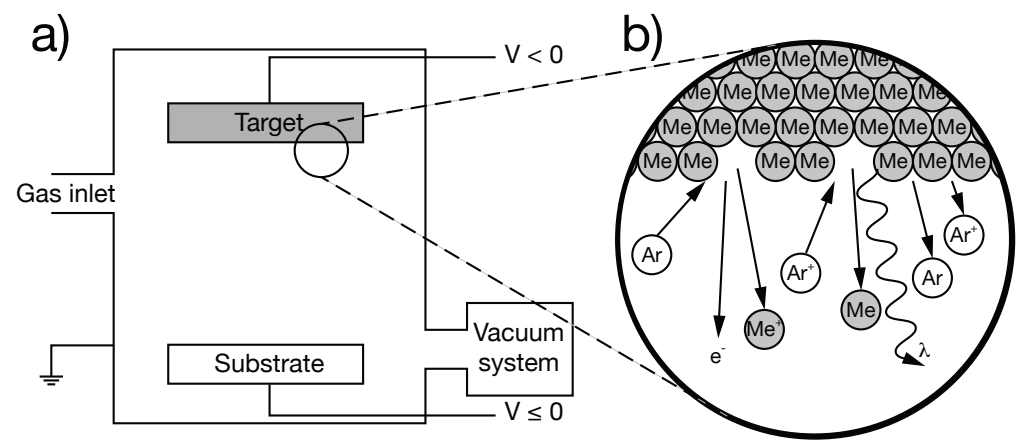

Figure 3.3 Sputtering: a) a schematic system setup and b) processes at a metal target surface

Since the vacuum chamber is grounded the electrons in the plasma will be accelerated not only toward the substrate but also towards the walls where they will leave the system. To more easily maintain the plasma, the electrons may be confined in the vicinity of the target surface with the help of a magnetron mounted behind the target. The magnetron will create a magnetic field close to the surface and trap the electrons in varying amounts depending on the magnetron setup. For planar magnetrons, which were used in this work, there are three different configurations described by Window and Savvides [32] and illustrated in Figure 3.4. This type of magnetron consist of two magnets; one cylindrical magnet in the center with the north pole closest to the target and one annular magnet at the perimeter with the south pole closest to the target. Depending on the strength of these two magnets the three types are acquired: unbalanced type I (Figure 3.4 a), balanced (Figure $3.4 \mathrm{~b}$ ), and unbalanced type II (Figure $3.4 \mathrm{c}$ ). In the type I configuration, the inner magnet is stronger than the outer, which disperse the magnetic field so that same field lines do not pass through the outer magnet, hence reducing the plasma density close to the substrate. In the opposite case 
the inner magnet is stronger than the outer so that the field lines are more dense at circumference. This is called a type II configuration and gives a large, but varying, flux of ions and electrons at the substrate. The balanced configuration is an intermediate, special case between type I and II, which will trap the charged species close to the target surface, but can only be approximated in practice.

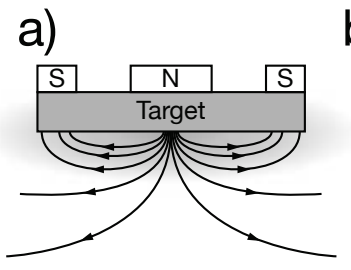

b)

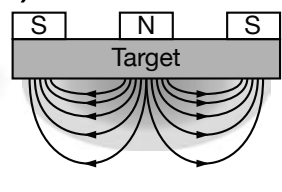

C)

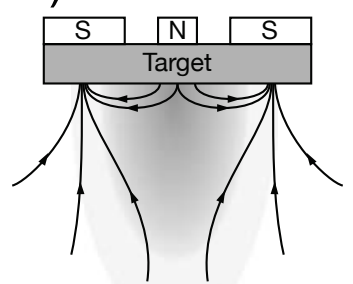

Substrate

Figure 3.4 Planar magnetron configurations based on the work by Window and Savvides [32]; a) unbalanced type I, b) balanced and c) unbalanced type II

As described in chapter 3.1 there are some parameters that can affect the growth conditions during deposition: temperature, ion flux and ion energy. The deposition temperature can be changed by heating the substrate, and the ion flux and energy can be varied by the addition of substrate bias and magnetic fields. The substrate bias will alter the electric field close to the substrate and thereby change the flux and energy of the incoming charged particles. The magnetic fields can be varied either by using electro magnets in the magnetrons [32] or by adding a pair of Helmholtz coils to produce an external field [33]. The direction of the external field can be set either in the same direction as that of the outer magnets of the magnetron, or in the opposite direction. The former configuration results in magnetic fields corresponding to a type II (Figure $3.4 \mathrm{c}$ ) while the latter result in type I (Figure 3.4 a). 


\section{4 Characterization Techniques}

\subsection{X-RAY DiFFraction (XRD)}

X-ray diffraction is a non-destructive technique for identifying a wide range of materials properties such as crystal phase and orientation. In principle X-rays are directed toward the sample where they interact with the atoms of the material and scatter in all directions. In some specific directions constructive interference will occur and give rise to strong intensity variations (peaks) if recorded at these specific angles. For most applications Bragg's law can be used to identify the angles for the constructive interference when the X-rays are diffracted by the periodicity of the crystal lattice planes, i.e. the positions of the peak maxima:

$$
n \lambda=2 d \sin \theta
$$

Here $n$ is an integer, $\lambda$ is the wavelength of the incoming X-rays, $d$ is the spacing between the diffracting planes and $\theta$ is the angle of the incident beams. Since the wavelength and the incidence angle during a measurement is known, the shortest inter-planar distance can be found for $n=1$.

A basic measurement setup, employed in Paper 2, is the symmetric $\theta-2 \theta$ technique where the angle of the outgoing X-rays satisfying Bragg's law is equal to the angle of the incident $\mathrm{X}$-rays, with respect to the sample surface. The effect is that only planes parallel to the sample surface will contribute to the detected peaks. In addition to the peak positions for determining lattice plane spacing, the shape of the peaks provides information; preferred orientation leads to increased peak width for the specific orientation and decreasing grain size gives rise to increasing peak width. For multilayer films additional peaks appear around some maxima, as for e.g. in Paper 2, fig 1. These peaks stem from the super- 
lattice (SL) reflections and can be utilized to determine the multilayer period $\Lambda$ of the film using

$$
\Lambda=\frac{m \lambda}{2\left(\sin \theta_{m}-\sin \theta_{B}\right)}
$$

where $m$ is the SL order, $\theta_{m}$ is the corresponding peak and $\theta_{B}$ is the (central) Bragg peak.

\subsection{Transmission Electron Microscopy Imaging}

Transmission electron microscopy (TEM) is to some extent similar to visible light (VL) microscopy - both are consisting of an illumination system and an imaging system - the main difference being that electrons instead of photons are used for illumination. The result is that the refracting media in VL optic lenses need to be replaced by electromagnets in electron microscopes and that the wavelength of electrons $(\lambda \sim 4 \mathrm{pm}$ at $100 \mathrm{kV}$ acceleration voltage) is much smaller than for visible light $(\lambda \sim 450-600 \mathrm{~nm})$. The former difference is a drawback when it comes to lens aberrations. Cylindrically symmetric electromagnetic lenses can only produce refraction corresponding to convex VL lenses. Another drawback is that electrons scatter a lot in air, hence the electron beam path and the sample must be under vacuum. But these drawbacks are compensated by the difference in wavelength for photons and electrons since the short wavelength of electrons allows for a significantly higher resolution $(<0.1 \mathrm{~nm})$ than VL $(\sim 300 \mathrm{~nm})$. This is the main advantage of TEM and because of this, a lot of research and development have been carried out to correct the lens aberrations. With a modern, corrected TEM, the environment of the microscope has come to be of more importance, since the resolution of such instruments is so small that even small vibrations, stray fields and temperature fluctuations affect the outcome of the acquisitions.

Another advantage of using electrons instead of photons is that it allows not only for high-resolution imaging but also for structural and chemical analysis as will be described later (4.3).

\subsubsection{TEM}

The illumination system, seen in Figure 4.1, consists of an electron gun where electrons are extracted and accelerated, usually to a few hundred $\mathrm{kV}$, followed by a condenser lens system. The role of the condenser system is to control the intensity and intensity spread of the electron beam on the sample by enhancing the coherency of the beam 
and demagnifying the image of the electron source on the front focal plane of the last lens in the condenser system usually called upper objective lens or C3 lens. The upper objective lens then controls the formation of the electron probe on the sample; parallel beam for conventional TEM (CTEM) and selected area electron diffraction (SAED) (Figure $4.1 \mathrm{a}$ ) and convergent beam for convergent beam electron diffraction (CBED) and scanning TEM (STEM) (Figure $4.1 \mathrm{~b}$ ).

a)

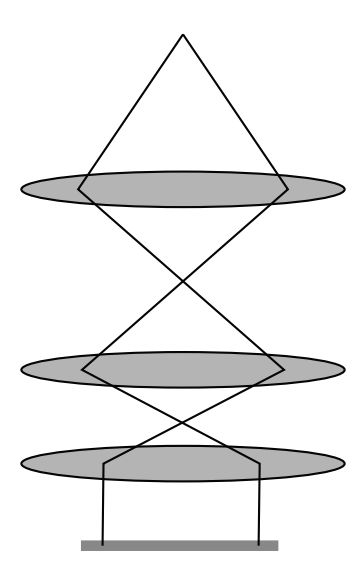

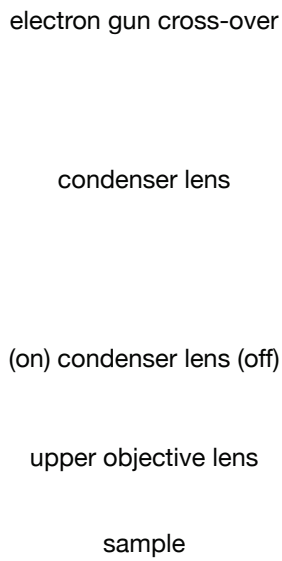

b)

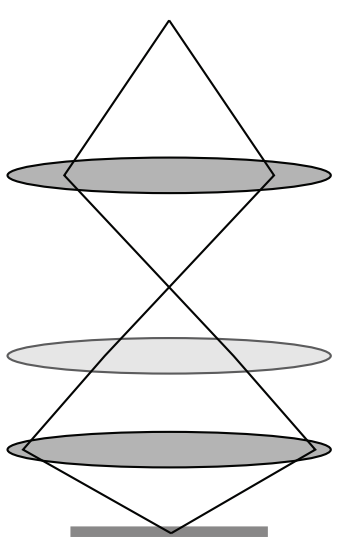

Figure 4.1 Overview of an illumination system of a TEM working in a) CTEM mode b) STEM mode

The incoming electron beam then interacts with the sample and is scattered by the sample atom electrons and nuclei by different amount, i.e. in different scattering angles. The transmitted and scattered electrons are then focused by the imaging lens system consisting of the lower objective lens, an intermediate lens and the projector lens. The imaging system can be set either to project the image of the sample (Figure $4.2 \mathrm{a}$ ), for CTEM, or the diffraction pattern (Figure $4.2 \mathrm{~b}$ ), for electron diffraction patterns and STEM, onto the final imaging plane. For CTEM usually either a fluorescent screen (for direct viewing) or a recording system such as a CCD camera (for direct viewing on a computer screen and saving) is placed in the last imaging or diffraction plane. 
a)

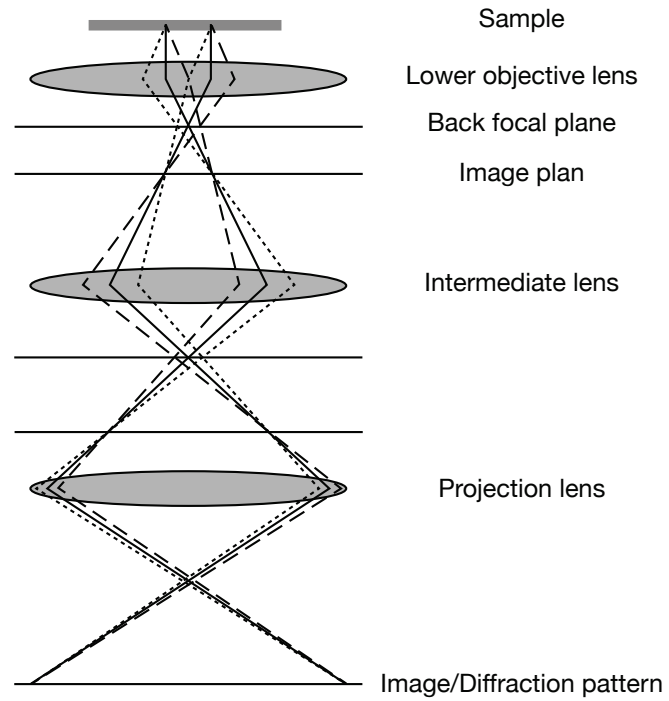

b)

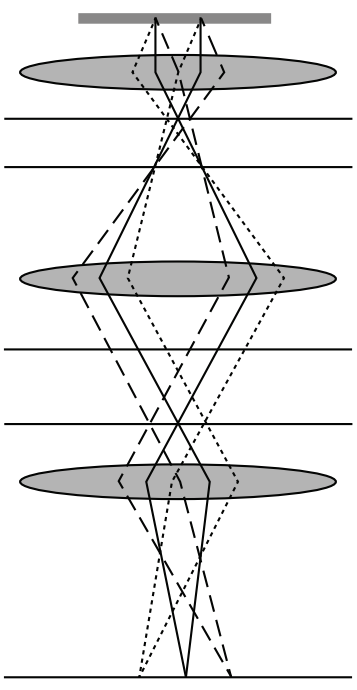

Figure 4.2 Imaging system in a) imaging mode and b) diffraction mode

\section{Electron-sample interactions}

The scattering events from the interaction of the electron beam with the sample atoms can simplistically be described as being either elastic or inelastic, i.e. the incoming electron loses, respectively, no or some energy to the sample. In principle, elastic scattering occurs mainly when these electrons interact with the sample atoms, seen as an interaction with a varying electric field (Figure $4.3 \mathrm{a}$ ) and is usually what is utilized for imaging the structure, while inelastic scattering involves interaction with individual sample electrons (Figure $4.3 \mathrm{~b}$ ), which is used for spectrometry (chapter 4.3).

a)

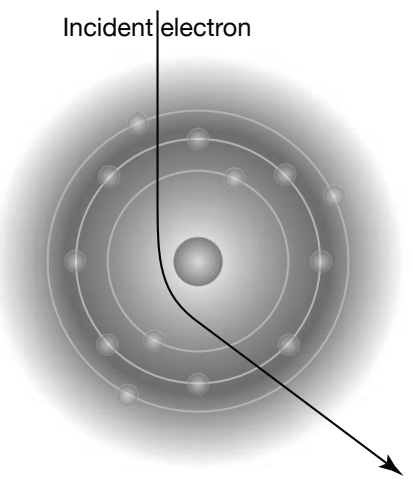

b)

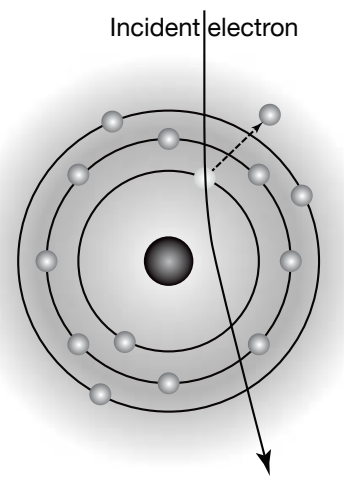

Figure 4.3 Example of a) elastic and b) inelastic interaction of an incident electron 
Elastic scattering is usually coherent and occurs at relatively low angles (Figure 4.4) but becomes more incoherent for angles $\geqslant 10^{\circ}$. Inelastic is instead almost always incoherent and scattered at very low angles $\left(<1^{\circ}\right)$. The difference in coherency is utilized in different imaging techniques where coherent scattering result in in-phase effects for diffraction contrast and incoherent scattering result in uncorrelated events useful for $Z$-contrast described below. All of these interactions can be seen in Figure 4.4.

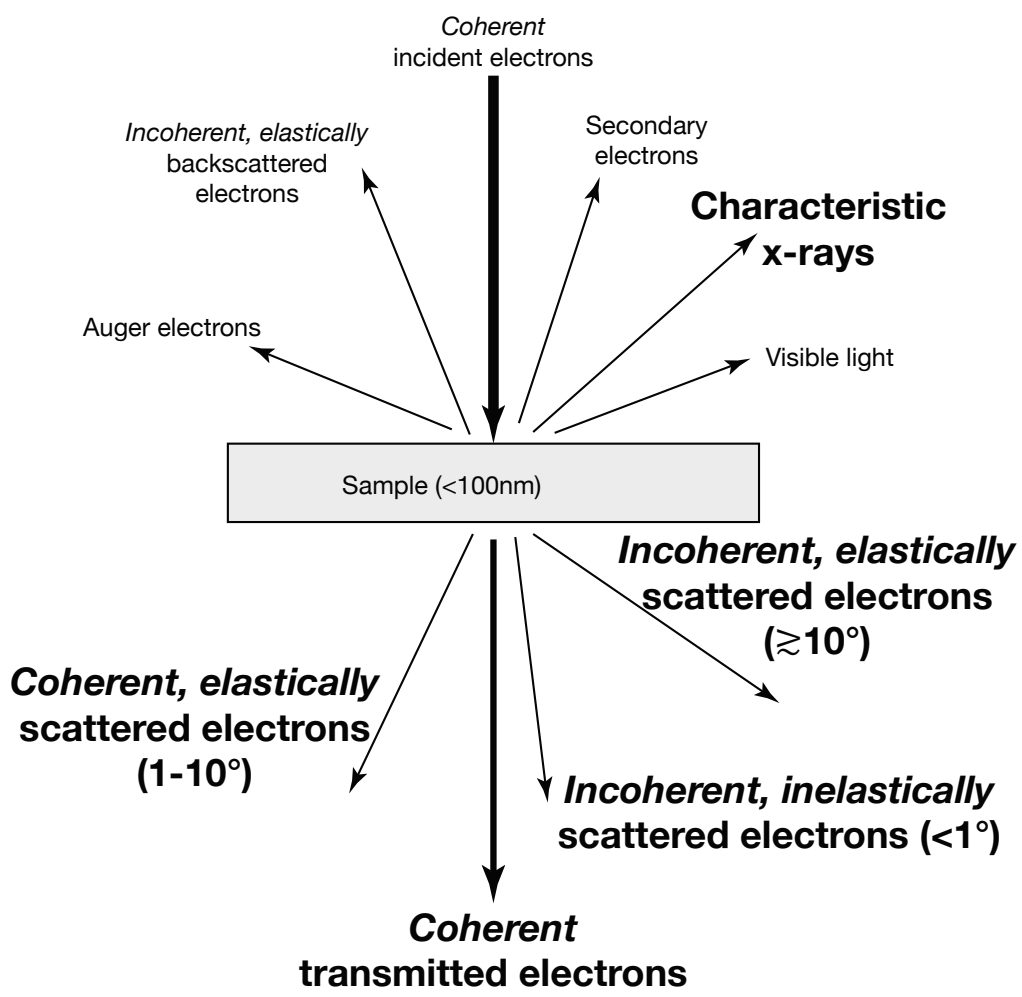

Figure 4.4 Electron interactions

\section{Electron diffraction}

An electron diffraction pattern in TEM can be achieved with either parallel illumination, as for SAED, or with a convergent beam, CBED. In a SAED the reciprocal space of a selected area of the sample is projected on the screen or recording device. This can be useful for retrieving information on the crystal structure, such as phase, orientation and texture, but it is also important for aligning the crystal to a low index zone axis for enabling high-resolution imaging. Since the specimen is usually more than one atomic layer (but preferably less than $10 \mathrm{~nm}$ ), the 
projection of the sample will show atomic columns, and not single atoms. In CBED the points in reciprocal space will be projected as disks, which enables e.g. determination of polarity, defects and the convergence angle of the electron probe on the sample. A CBED pattern will also be shown in STEM mode where the pattern of disks will be projected on a selected detector (see below in 4.2.2).

\section{Contrast formation}

The contrast in TEM images can be formed either by amplitude contrast or phase contrast. The distinction is that the former builds up images from primarily one beam while in the latter images are formed by interference of several beams. However, it can be hard to acquire an image with solely one of the contrast types.

Amplitude contrast images are formed either in bright-field (BF) mode, where ideally only the transmitted (unscattered) beams are selected by the objective aperture, or dark-field (DF) mode, where only one angle of the diffraction is selected, see Figure 4.5. One amplitude contrast mechanism arise because of variations of the mass, density and/or the thickness of the sample that cause the beam electrons to be scattered by different amounts giving rise to what is called mass-thickness contrast. Another amplitude contrast mechanism occurs if the sample is crystalline. In that case the atomic planes will, similarly to what happens in $\mathrm{XRD}$, diffract the beam so that constructive interference arises for angles satisfying the Bragg condition (equation 1), resulting in what is called Bragg-diffraction contrast. The electrons in such an interaction are elastically and coherently scattered. This type of scattering can also occur for crystal defects and therefore all such elastically and coherently scattered electrons are said to cause diffraction contrast. For low angles $\left(\$ 5^{\circ}\right)$ both mass-thickness and diffraction contrast contribute to the image, but for higher angles the scattering of the electrons depends mostly on atomic number, $Z$, and the contrast is hence called $Z$-contrast. 

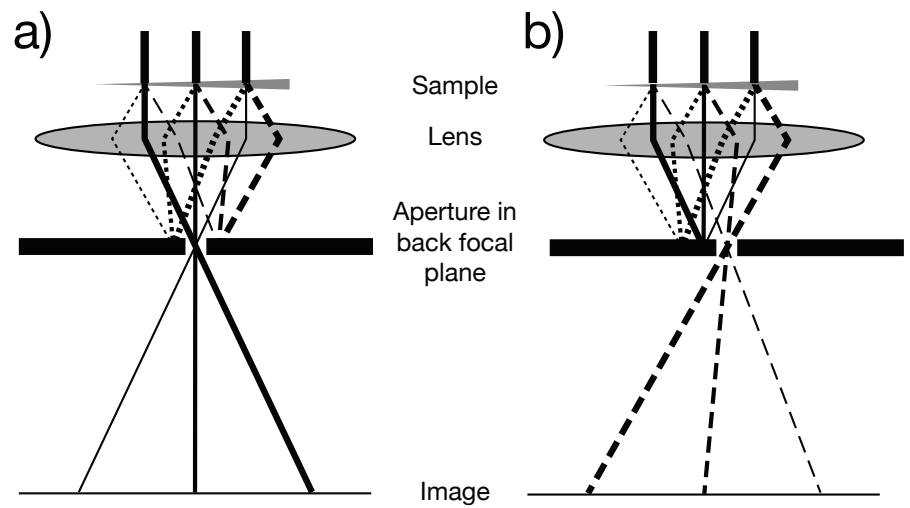

Figure 4.5 Contrast formation in CTEM by a) BF or b) DF

Phase contrast is formed whenever the lower objective aperture is selecting more than one beam. This is the main contrast used for highresolution TEM (HR-TEM) imaging. If the sample to be imaged is thin it can be seen as a phase object, i.e., the electron wave function will be phase shifted when passing through the sample. For very thin samples the phase shift is approximately proportional to the electric potential created by the atoms and electrons in the sample. The exiting electron wave front will therefore have a phase modulation that reflects the electric potential. However, this wave front will also pass through the objective lens (in reality a whole system of lenses), which for any real microscope will distort the wave front due to lens aberrations. These aberrations will cause information in the sample to be delocalized in the image. This means that the image will consist of overlapping information representing the points in the sample so that the image is a combination of the sample potential variation and the interference of this information. Therefore it is important to remember that HR-TEM will most often only give information about the structure such as orientation and spacing of the lattice planes, i.e. spatial frequency, in the sample - and only in a limited parameter space (e.g. a few nm thick samples of preferentially light elements) the actual position of atoms and lattice planes.

How the information from the sample, i.e. the electron wave front leaving the sample, is transferred to an image can be theoretically described by a transfer function, which consists of the contrast (or intensity) dependence of the apertures, attenuation of the electron wave and aberrations of the lenses. The largest contribution to lens aberrations is spherical and chromatic aberration. With the last generation of electron microscopes, spherical aberration $\left(C_{s}\right)$ is corrected by a system of lenses that are non-rotationally symmetric. Such a system can be positioned either in the illumination system (probe correction) or the imaging system 
(image correction) or both. Chromatic aberration $\left(C_{c}\right)$ is usually overcome by introducing a monochromator in the illumination system. If $C_{s}$ is not corrected for, information will be spread since a point in the sample will not be focused to the same plane in the image. This means that lattice fringes may be delocalized so that they seem to appear outside the sample or grain, spatial frequency information may be inverted and the resolution will be worse than for a corrected TEM.

\subsubsection{STEM}

In STEM the image is not created by a projection of the scattered electron beam. Instead a convergent beam is probed over the sample where the scattered electrons at each point will be recorded by a detector. The intensity of a certain point in the sample will therefore be given by the amount of the scattered electrons that falls onto the selected detector.

The detectors available in STEM are a BF detector, an annular DF (ADF) detector and a high angle ADF (HAADF) detector as can be seen in Figure 4.6. Depending on the camera length, i.e. the virtual distance between the sample and the detector, the electrons scattered in a specific angular interval will be detected. In BF and ADF the scattering angles are relatively low and contrast is formed both from mass-thickness variations and diffraction. But for HAADF the scattering angle is large enough so that incoherent electrons and hence Z-contrast is dominating the intensity, enabling contrast distinction of different elements. This can be further proven by additional spectrometry, which will be presented in chapter 4.3. However Z-contrast is mostly beneficial for heavy atoms since the intensity in the image is proportional to $Z^{2}$. For enhancing the contrast of lighter elements, a quite new technique called annular BF $(\mathrm{ABF})$ can be used. In $\mathrm{ABF}$, the primary CBED disk is magnified to cover the entire ADF detector which makes it a BF technique but without the elements of the central part of the beam. As such it promotes imaging of both light and heavy elements [34]. 


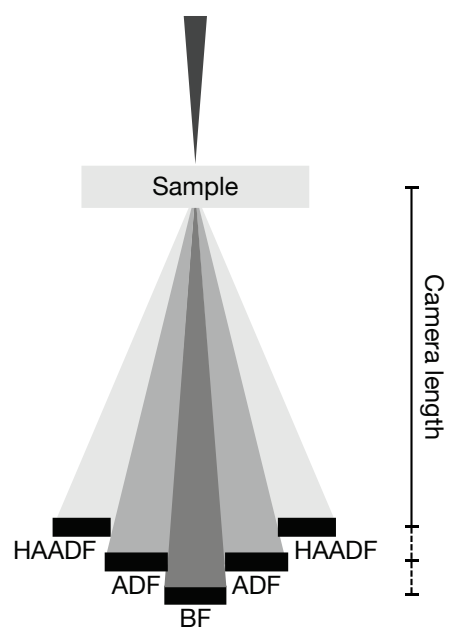

Figure 4.6 Detectors in STEM

A characteristic feature of STEM using an annular detector is that since the detector covers an area, interference minima and maxima due to the interaction with sample lattice will be averaged. This means that the detection only depends on the total intensity, which leads to a straightforward interpretation. If the sample is aligned to a low-index zone axis, atomic columns will be seen as bright contrast at their actual position.

An important aspect of all TEM imaging, CTEM as well as STEM, is that the beam is transmitted through the sample. Even though we try to make the sample as thin as possible it is difficult to achieve only a few atomic layers (and even so, such a thin sample would most often not give enough contrast). This has the effect that we are always projecting a volume (three dimensions) of the sample into a two-dimensional image. Therefore nanocomposite materials, where the grains may be smaller than the sample thickness and have a sharp curvature, can be difficult to image, while two-dimensional structures such as multilayers enables a more precise description in TEM as can be seen in Figure 4.7.
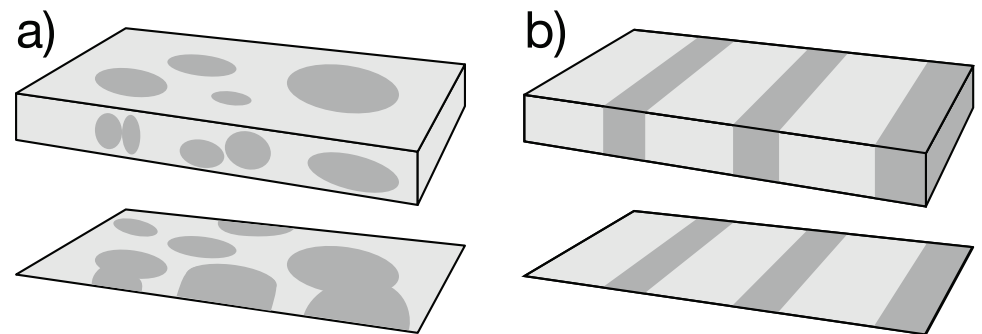

Figure 4.7 Projection of a thin sample from a) a nanocomposite sample and b) a multi-layer structured sample 


\subsection{TEM SPEGTROSGOPY}

Spectrometry in a transmission electron microscope is based on the inelastic scattering of the beam electrons impinging on the sample, i.e. the incoming electrons that lose energy in the interaction with a sample atom. The energy lost by the incident electron will excite an atom in the sample (Figure $4.8 \mathrm{a}$ ). The amount of energy loss $(\Delta E)$ depends on the possible excited states of the affected atom in the sample and this energy loss is what is measured in electron energy loss spectrometry (EELS). When the atom relaxes to its ground state, a low energy Auger electron or a photon is emitted (Figure $4.8 \mathrm{~b}$ ). For heavier elements photon emission is the favored de-excitation mechanism. The energy of such an emitted photon depends on the energy difference between the levels of the electron transition involved and is characteristic for every element. In the case of X-ray photons the energy is detected in an analysis called energy dispersive X-ray (EDX) spectrometry.

a)

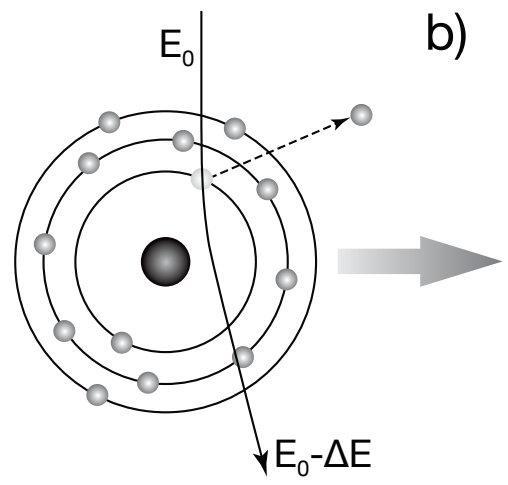

b)

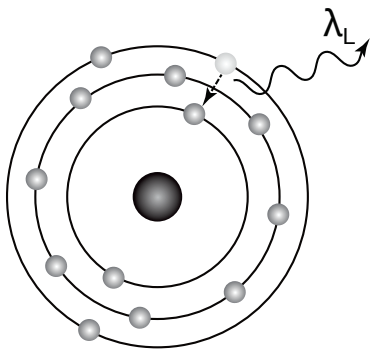

Figure 4.8 Inelastic interaction where a) the beam electron excites the atom and then b) the atom relaxes by emitting an X-ray photon

\section{Spectrum Imaging}

Modern microscopes are quite fast in obtaining both EDX and EEL spectra. Together with drift correction, this allows for high resolution, two-dimensional scans where a spectrum is measured at each position/ pixel resulting in a three-dimensional set of data (Figure 4.9). This technique is called spectrum imaging (SI) and can provide near atomic resolution elemental information for both EDX [35] and EELS [36]. 


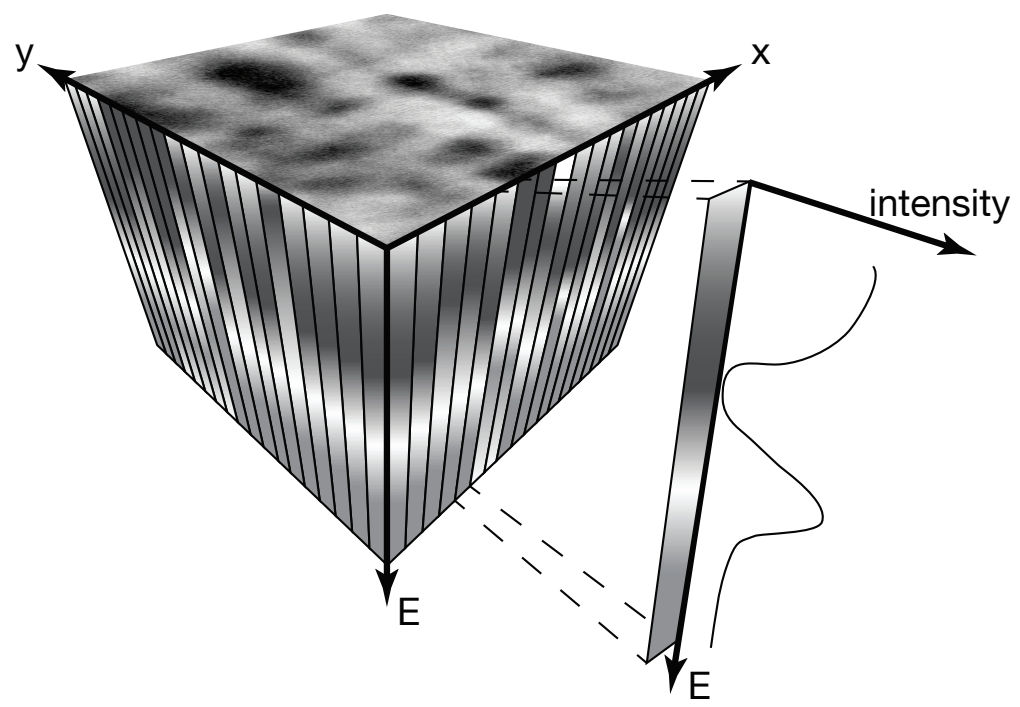

Figure 4.9 Spectrum imaging data cube, indicating the projected sample image in the $\mathrm{x}-\mathrm{y}$ plane and the energy spectrum in the perpendicular direction

\subsection{1 $E D X$}

In EDX the characteristic emission energy of an excited sample atom is recorded by detecting the energy of the emitted X-ray photons $(E=h c / \lambda)$. To avoid mistaking two photons for one the counting time for the detector must be small enough compared to the photon flux, which limits the energy resolution compared to EELS ( $\sim 100$ times lower). Other drawbacks are inefficient collection (a few \% compared to almost $100 \%$ for EELS) and the protecting window, between the microscope column and the detector, filtering out low energies, which impedes the detection of elements with low $Z(\leqslant 11)$. On the other hand heavier elements can be difficult to detect with EELS, and EDX still have $~ 10-20$ times better energy range.

In Paper 2, EDX analysis was utilized for chemical mapping of one of the samples. Such a chemical map can be achieved by selecting an element specific peak (an energy window) from each spectrum in a spectrum image. The intensity of the peak will give the intensity for each pixel in the image. If this is carried out for every elemental peak of interest, the intensity for each image can be set to a specific color so that the separate elemental maps can be interweaved into one, as e.g. in Figure 6 of Paper 2. 


\subsubsection{EELS}

Since EELS enables relatively high energy resolution, fine details of the spectrum can, in addition to elemental analysis, be employed to analyze chemical and physical properties of the studied sample. Depending on the properties to be studied the focus is put on a specific region of the achieved spectrum. Usually the spectrum is divided into a zero-loss region, a low-loss region $(\$ 50 \mathrm{eV})$ and a high-loss region $(\gtrsim 50 \mathrm{eV})$ seen in Figure 4.10. The zero-loss region contains the zero-loss peak, which gives the intensity of the elastically scattered electrons. This peak is the most prominent feature of the spectrum but is usually only utilized for giving a measure of the resolution by taking the full width at half maximum of the peak. The low-loss region displays the energy loss for electron interaction causing collective excitation of the outermost electrons in the atoms, such as plasmon excitations. The dominant features of the low-loss region result from the resonant plasmon oscillations of the valence electrons and interband transitions from valence to conduction bands. The last region, the high-loss region, include the energy losses from electron interaction with core electrons and therefore is usually called the core-loss region and will be described in more detail below.

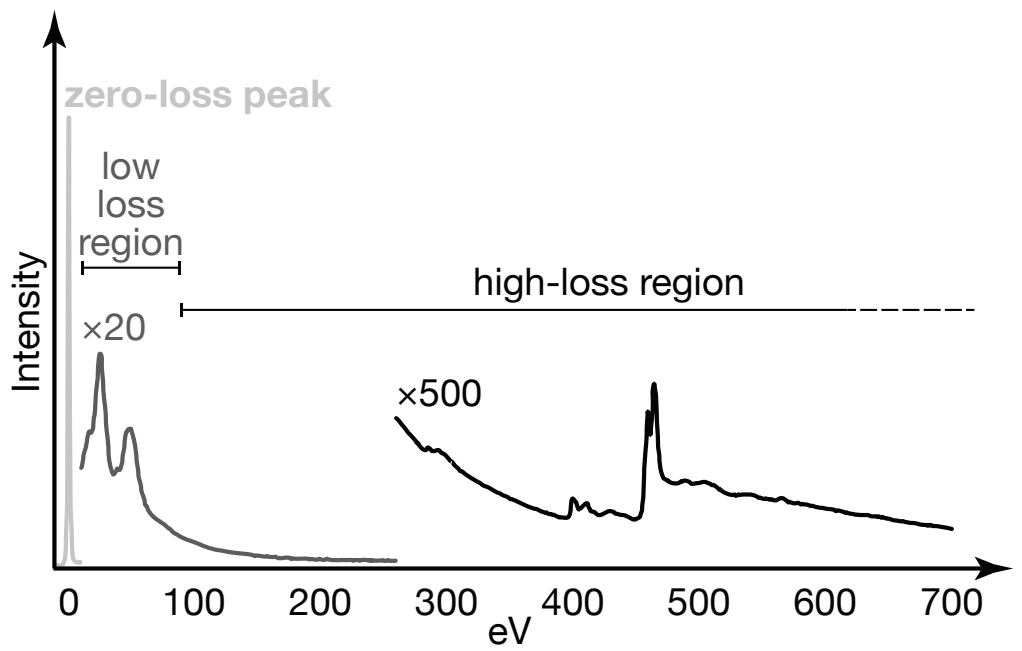

Figure 4.10 Example of EEL spectrum including the zero-loss peak, low-loss region and high-loss region

To be able to detect the energy loss of the scattered electrons a spectrometer must be inserted between the sample and the detector. The most common type of spectrometer is the sector magnet spectrometer creating a homogenous magnetic field normal to the incoming electrons. Because the electrons have the same charge but different velocity, the magnetic force will deflect the electrons by different amount. The 
velocity in turn depends on the energy of the electron and so the electrons of varying energy will be dispersed on the detector. This is a similar manner to the operation of a monochromator, but the monochromator is followed by a slit instead of a detector, to select a specific energy/velocity. After the electrons have been dispersed in the spectrometer, the detector records the incoming electrons for each energy channel in parallel and the signal is displayed as a spectrum.

\section{Core Loss EELS}

When a beam electron excites an atom, the ejected electron will, given enough energy, find a new unoccupied state above the Fermi level $\left(E_{F}\right)$, while the beam electron loses a corresponding energy. The final energy of the transition is given by the probability for the core electron to make that particular transition from ground state to above the $E_{F}$. In principle, the higher the transition energy the less likely is the electron to make it. The minimum amount of energy needed for this transition is called critical ionization energy, $E_{C}$. If the excited atom is isolated, the unoccupied density of states (DOS) above $E_{F}$ will have a smooth distribution, and will be seen in an EEL spectrum as a sharp ionization edge ideally starting at $E_{C}$, followed by a gradual decline. But in a solid material, where the atoms cannot be considered as isolated, the DOS may become more complex due to the modification by chemical bonding and hence the empty states above the Fermi energy will contain additional features. Energy lost by the beam electron in excess of the threshold energy will therefore reflect the unoccupied DOS of the probed atom species in the material, as can be seen in Figure 4.11, where the features of the energy loss spectrum will reflect the crystallographic structure, chemical bonding and bond length of neighboring atoms. This information is reflected as an oscillating intensity for excess energy in the range $\sim 0-30 \mathrm{eV}$ above the edge onset. These oscillations are known as electron energy loss near-edge structure (ELNES) and are shown in Figure 4.11. For a range of materials such as transition metals and especially inorganic compounds of carbides, nitrides and oxides, the ELNES will provide information about the number of atoms and their geometry within the first coordination shell [37], which was utilized in Paper 1. In addition ELNES can be used for determining the formal valency of an element [38]. For high signal to noise measurements, weaker oscillations may be found for energy losses of $\gtrsim 50 \mathrm{eV}$ above $E_{C}$ and are called extended energy-loss fine structure (EXELFS), also shown in Figure 4.11, and provide short-range information, such as bond length. 


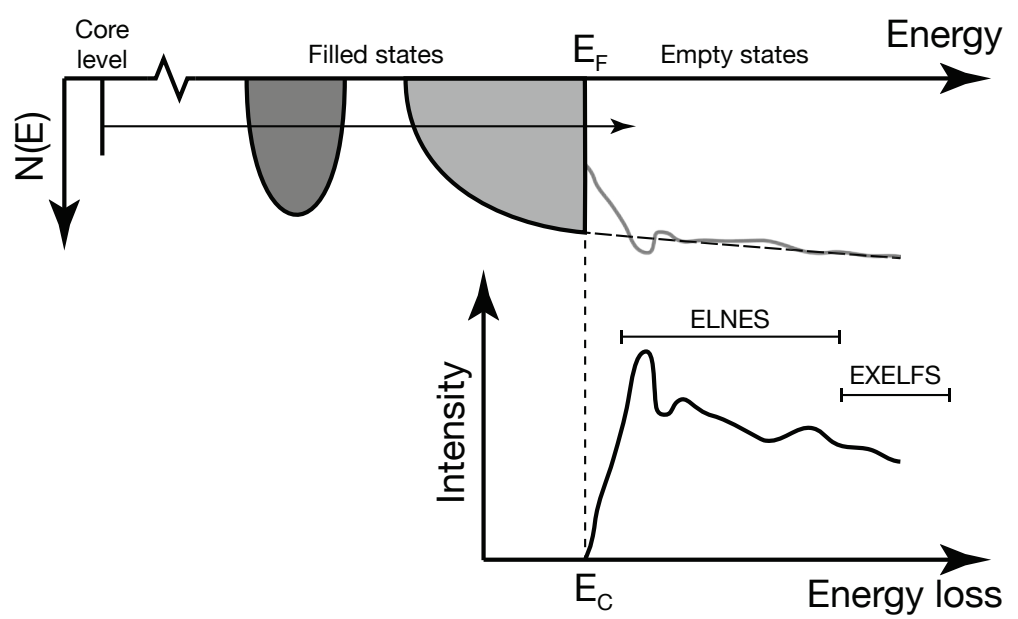

Figure 4.11 Relationship between the unoccupied DOS $(\mathcal{N}(E))$ and the corresponding ionization edge in the core-loss EEL spectra. After Brydson and Hondow [39]

Due to random, plural inelastic scattering events the ionization edges will always be superimposed on a rapidly decreasing, continuous background. In addition, if the sample thickness is greater than the mean free path for inelastic scattering plasmon intensities will increase causing additional features $\sim 15-25 \mathrm{eV}$ above any ionization edge as a result of plural scattering (both plasmon scattering and core loss scattering). To minimize misinterpretation of core-loss EEL spectra both effects should be removed. The continuous background can be subtracted by e.g. curve fitting to an energy window right before the ionization edge of interest while the plasmon related effects may be removed by Fourier transformation deconvolution with the corresponding low-loss spectrum. Spectral noise from such procedures and other sources may be reduced by averaging spectra from an area in a SI, as was the case for the spectra in Paper 1. 


\section{5 \\ Summary of Papers}

\subsection{PAPER 1}

In this paper the structure of metastable cubic $\mathrm{SiN}_{\mathrm{x}}$ was investigated by high-resolution STEM and spatially resolved core loss EELS. The results were also compared to image simulations and ab-initio fine structure calculations.

The $\operatorname{SiN}_{\mathrm{x}}$ was epitaxially stabilized in multilayers consisting of $40 \AA$ layers of TiN and $13 \AA$ layers of $\mathrm{SiN}_{\mathrm{x}}$ on a $50 \mathrm{~nm}$ thick TiN seed layer grown on a $\mathrm{MgO}(001)$ substrate.

The high-resolution ABF-STEM images showed a crystal structure of the $\mathrm{SiN}_{\mathrm{x}}$ that reproduced that of the TiN in both $\left.<100\right\rangle$ and $\left.<110\right\rangle$ directions and when compared to image simulations were found to correspond well with the B1 structure.

For the core-loss EEL spectra of the N-K edge, the ELNES was used to determine the coordination of the $\mathrm{N}$ atoms in the TiN and $\mathrm{SiN}_{\mathrm{x}}$ layers. The N-K edge for TiN corresponded to previous measurements of bulk TiN and also matched the calculated ELNES spectrum. Since the candidate structures of cubic $\mathrm{SiN}_{\mathrm{x}}$ do not exist in bulk, this spectrum could only be compared to the calculated spectra. Two ELNES spectra were calculated for $\mathrm{SiN}_{\mathrm{x}}$, one for a B1 configuration and one for B3. The experimental ELNES spectrum was most consistent with the former, i.e. also the EELS study indicates a B1 like structure of the $\mathrm{SiN}_{\mathrm{x}}$.

\subsection{PAPER 2}

Also in the second paper the structure of $\mathrm{SiN}_{\mathrm{x}}$ in a $\mathrm{T}_{\mathrm{m}} \mathrm{N}$ multilayer was studied by high-resolution STEM and spectrometry (here EDX). However, in this case no cubic $\mathrm{SiN}_{\mathrm{x}}$ was found. Instead the $\mathrm{SiN}_{\mathrm{x}}$ was found to be amorphous for all samples studied. 
The investigated samples were grown on the same type of substrates as the $\mathrm{TiN} / \mathrm{SiN}_{\mathrm{x}}$ multilayers, i.e. $\mathrm{MgO}(001)$. First a seed layer of $50 \mathrm{~nm}$ was grown on each substrate and then followed 30 periods of $40 \AA \mathrm{ZrN}$ and intended thicknesses of either 2, 4, 6, 8 or $15 \AA$ of $\mathrm{SiN}_{\mathrm{x}}$. For all $\mathrm{SiN}_{\mathrm{x}}$ thicknesses the multilayers were grown with a substrate temperature of $800{ }^{\circ} \mathrm{C}$ and for a $6 \AA$ thickness one sample was also grown at $500^{\circ} \mathrm{C}$.

For all samples, independent of layer thickness and substrate temperature, the $\mathrm{SiN}_{\mathrm{x}}$ was found to be amorphous. For the samples grown at $800{ }^{\circ} \mathrm{C}$ with 2 and $4 \AA \mathrm{SiN}_{\mathrm{x}}$ intended thickness, the films were epitaxial throughout. However, it is only the $\mathrm{ZrN}$ that grows epitaxially - the $\mathrm{SiN}_{\mathrm{x}}$ forms precipitates at grain boundaries and surface defects of the $\mathrm{ZrN}$. This results in a columnar distribution of the $\mathrm{ZrN}$ and $\mathrm{SiN}_{\mathrm{x}}$, which was further shown by chemical mapping using EDX. In contrast, the layers of 8 and $15 \AA \mathrm{SiN}_{\mathrm{x}}$ grown at $800^{\circ} \mathrm{C}$ and $6 \AA$ grown at $500{ }^{\circ} \mathrm{C}$ the $\mathrm{SiN}_{\mathrm{x}}$ layers grow continuous amorphous layers causing the succeeding $\mathrm{ZrN}$ layers to be polycrystalline. For the sample with $6 \AA \mathrm{SiN}_{\mathrm{x}}$ grown at $800{ }^{\circ} \mathrm{C}$ the structure seems to be a transition where columnar $\mathrm{SiN}_{\mathrm{x}}$ precipitates are seen but that are more laterally extending. In this sample the epitaxy is not extending through the whole film.

\subsection{COMPARISON}

$\mathrm{SiN}_{\mathrm{x}}$ is obviously difficult to stabilized in a cubic structure. Even though $\mathrm{TiN}$ and $\mathrm{ZrN}$ have similar properties and the same crystalline structure, the difference in lattice parameter of $8 \%$ is enough to enable epitaxial stabilization of $\mathrm{SiN}_{\mathrm{x}}$ between $\mathrm{TiN}$ layers but not between $\mathrm{ZrN}$. Perhaps this instability is one explanation to why it is so difficult to theoretically determine the actual crystal structure of cubic of $\mathrm{SiN}_{\mathrm{x}}$.

Another difference between the two studied multilayers is the separation of the $\mathrm{T}_{\mathrm{m}} \mathrm{N}$ and $\mathrm{SiN}_{\mathrm{x}}$. In the case of the transition metal being $\mathrm{Ti}$ the separation is lateral, i.e. the film consists of continuous layers, for both epitaxial and polycrystalline/amorphous multilayers (for samples of other thicknesses than that in Paper 1, see e.g. the dissertation by H. Söderberg [40]). But when the transition metal is $\mathrm{ZrN}$ the separation is both lateral and vertical, with the $\mathrm{SiN}_{\mathrm{x}}$ forming columnar precipitates, for epitaxial films and lateral only for polycrystalline/amorphous films. An example of the structural difference can be seen in Figure 5.1 where the samples were grown with a (intended) $\mathrm{SiN}_{\mathrm{x}}$ thickness of $5 \AA$ (for $\mathrm{TiN} / \mathrm{SiN}_{\mathrm{x}}$ ) and $4 \AA$ (for $\mathrm{ZrN} / \mathrm{SiN}_{\mathrm{x}}$ ). 


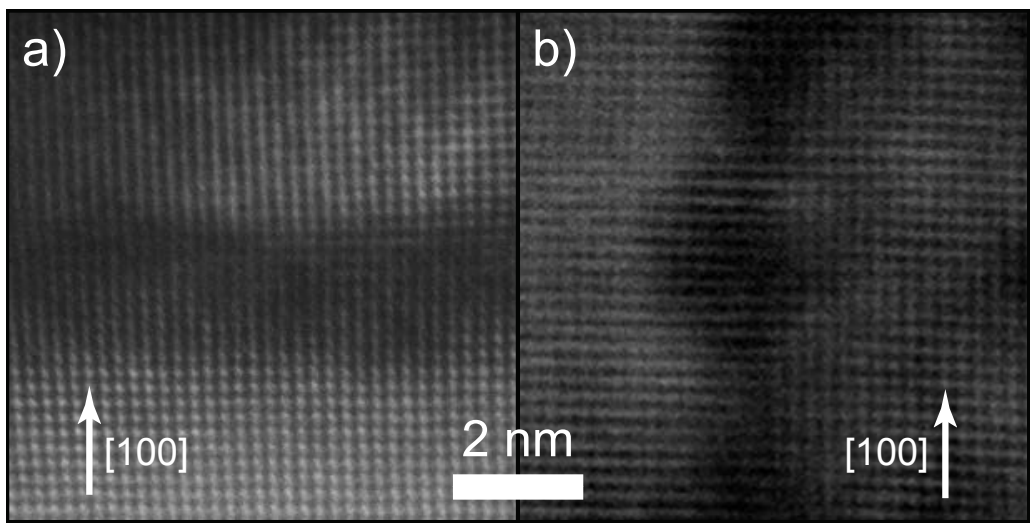

Figure 5.1 Comparison of a) $\mathrm{TiN} / \mathrm{SiN}_{\mathrm{x}}$ and b) $\mathrm{ZrN}_{\mathrm{SiN}}$

\subsection{FUTURE WORK}

In a similar manner to the $\mathrm{TiN} / \mathrm{SiN}_{\mathrm{x}}$ multilayer in Paper 1, the ELNES of the hardest $\mathrm{TiN} / \mathrm{SiN}_{\mathrm{x}}$ and other $\mathrm{T}_{\mathrm{m}} \mathrm{N} / \mathrm{SiN}_{\mathrm{x}}$ nanocomposites can be analyzed to see if the $\mathrm{N}-\mathrm{K}$ edge of $\mathrm{SiN}_{\mathrm{x}}$ is similar to the Bl structure. Further studies could also be performed on other $\mathrm{T}_{\mathrm{m}} \mathrm{N} / \mathrm{SiN}_{\mathrm{x}}$ multilayers could be studied, preferably of a $\mathrm{T}_{\mathrm{m}} \mathrm{N}$ with lattice parameter smaller than for TiN (or at least smaller than $\mathrm{ZrN}$ ), to see if epitaxy can be achieved. Obviously, the lattice parameter of $\mathrm{ZrN}$ is too large. But although the lattice match is better for $\mathrm{TiN}$ it is not necessarily the best match.

In addition, other structures for cubic $\mathrm{SiN}_{\mathrm{x}}$ than the two suggested (B1 and B3) could be simulated, to see if there is any structure that can also be theoretically proven to exist.

An additional measurement that could bring more insight to the $\mathrm{T}_{\mathrm{m}} \mathrm{N} / \mathrm{SiN}_{\mathrm{x}}$ multilayers and nanocomposites is atom probe tomography to determine the stoichiometry of $\mathrm{SiN}_{\mathrm{x}}$, i.e. determine the $\mathrm{x}$. This could also help in sorting out probable structures of the metastable cubic $\operatorname{SiN}_{\mathrm{x}}$. 


\section{References}

[1] S. Veprek, M. Haussmann, S. Reiprich, Li Shizhi, J. Dian, Surface and Coatings Technology, 86-87 (1996) 394

[2] A. Hörling, L. Hultman, M. Odén, J. Sjölén, L. Karlsson, fournal of Vacuum Science and Technology A, 20 (2002) 1815

[3] Y.-H. Chen, K.W. Lee, W.-A. Chiou, Y.-W. Chung, L.M. Keer, Surface and Coatings Technology, 146-147 (2001) 209

[4] Powder diffraction file, card No. 38-1420, JCPDS - International Center for Powder Diffraction Data (1998)

[5] L. E. Toth, Transition Metal Carbides and Nitrides, Academic Press, New York and London, 1971

[6] J.-E. Sundgren, B.O. Johansson, A. Rockett, S.A. Barnett, J.E. Greene, Physics and Chemistry of Protective Coatings, edited by W.D. Sproul, J.A. Thornton, American Institute of Physics, Universal City, 1985

[7] G. Gagnon, J.F. Currie, J.L. Brebner, T. Darwall, Fournal of Applied Physics, 79 (1996) 7612

[8] H. Ljungcrantz, M. Odén, L. Hultman, J.E. Greene, J.-E. Sundgren, Fournal of Applied Physics, $\mathbf{8 0}$ (1996) 6725

[9] H. Ljungcrantz, C. Engström, M. Olsson, X. Chu, M.S. Wong, W.D. Sproul, L. Hultman, Fournal of Vacuum Science and Technology A, 16 (1998) 3104

[10] H.G. Tompkins, Journal of Applied Physics, 70 (1991) 3876

[11] S. Niyomsoan, W. Grant, D.L. Olson, B. Mishra, Thin Solid Films, 415 (2002) 187

[12] Powder diffraction file, card No. 35-0753, JCPDS - International Center for Powder Diffraction Data (1998)

[13] W.D. Sproul, Thin Solid Films, 107 (1983) 141

[14] L. Krusin-Elbaum, M. Wittmer, Thin Solid Films, 107 (1983) 111 
[15] I. Tomaszkiewicz, Fournal of Thermal Analysis and Calorimetry, 65 (2001) 425

[16] A. Zerr, G. Miehe, G. Serghiou, M. Schwarz, E. Kroke, R. Riedel, H. Fueß, P. Kroll, R. Boehler, Nature, 400 (1999) 340

[17] J.Z. Jiang, F. Kragh, D.J. Frost, K. Ståhl, H. Lindelov, Fournal of Physics: Condensed Matter, 13 (2001) L515

[18] I. Tanakaa, F. Oba, T. Sekine, E. Ito, A. Kubo, K. Tatsumi, H. Adachi, T. Yamamoto, Fournal of Materials Research, 17 (2002) 731

[19] S.R. Elliot, Physics of Amorphous Materials, Longman, London and New York, 1983

[20] E. Martinez, R. Sanjines, A. Karimi, J. Esteve, F. Levy, Surface and Coatings Technology, 180-181 (2004) 570

[21] H. Söderberg, J.M. Molina-Aldareguia, T. Larsson, L. Hultman, M. Odén, Applied Physics Letters, 88 (2006) 191902

[22] L. Hultman, J. Bareño, A. Flink, H. Söderberg, K. Larsson, V. Petrova, M. Odén, J.E. Greene, I. Petrov, Physical Review B, 75 (2007) 155437

[23] T. Marten, B. Alling, E.I. Isaev, H. Lind, F. Tasnádi, L. Hultman, I.A. Abrikosov, Physical Review B, 85 (2012) 104106

[24] S. Veprek, M.G.J. Veprek-Heijman, P. Karankova, J. Prochazka, Thin Solid Films, 476 (2005) 1

[25] S. Veprek, M. Haussmann, S. Reiprich, L. Shizhi, J. Dian, Surface and Coatings Technology, 86-87 (1996) 394

[26] M. Nose, M. Zhou, T. Nagae, T. Mae, M. Yokota, S. Saji, Surface and Coatings Technology, 132 (2000) 163

[27] H. Söderberg, M. Odén, A. Flink, J. Birch, P.O.Å. Persson, M. Beckers, L. Hultman, Fournal of Materials Research, 22 (2007) 3255

[28] M. Ohring, The Materials Science of Thin Films, Academic Press, San Diego, 1992

[29] P.B Barna and M. Adamik, Thin Solid Films, 317 (1998) 27

[30] L. Jastrzebski, Journal of Crystal Growth, 63 (1983) 493 
[31] B. Beaumont, P. Vennéguès, P. Gibart, Physica Status Solidi (b), 227 (2001) 1

[32] B. Window and N. Savvides, Fournal of Vacuum Science and Technology A, 4 (1986) 196

[33] I. Petrov, F. Adibi, J.E. Greene, W.D. Sproul, W.-D. Münz, fournal of Vacuum Science and Technology A, 10 (1992) 3283.

[34] S.D. Findlay, N. Shibata, H. Sawada, E. Okunishi, Y. Kondo, T. Yamamoto, Y.Ikuhara, Applied Physics Letters, 95 (2009) 191913

[35] M. Watanabe, Atomic Level Characterization for New Materials and Devices '09, The 141 1 st Committee on Microbeam Analysis, Japan Society for the Promotion of Science (2009) 400

[36] M. Bosman, V.J. Keast, J.L. García-Muñoz, A.J. D’Alfonso, S.D. Findlay, L.J. Allen, Physical Review Letters, 99 (2007) 086102

[37] V.J. Keast, A.J. Scott, R. Brydson, D.B. Williams, J. Bruley, fournal of Microscopy, 203 (2001) 135

[38] G.C. Galvert, A. Brown, R. Brydson, Fournal of Electron Spectroscopy and Related Phenomena, 143 (2005) 173

[39] R. Brydson, N. Hondow, Electron Energy Loss Spectrometry and Energy Dispersive X-ray Analysis. In Aberration-Corrected Analytical Transmission Electron Microscopy, R. Brydson (ed.), 163-210.

Chichester, John Wiley \& Sons Ltd., 2011

[40] H. Söderberg, Growth and Characterization of TiN/SiN ${ }_{x}$ Multilayer Thin Films, Dissertation 2006:59, Luleå University of Technology, 2006 


\section{Papers}

The articles associated with this thesis have been removed for copyright reasons. For more details about these see:

http://urn.kb.se/resolve? urn=urn:nbn:se:liu:diva-102176 